\title{
Agrotóxicos: falsas premissas e debates
}

\author{
The false premises of pesticide use
}

Antônio Elísio Garcia Sobreira 1

Paulo J osé A dissi 2

\footnotetext{
1 Departamento de Engenharia de Produção. GEA/UFPB, Centro de Tecnologia. C.P. 5.045, 58047-970, João Pessoa PA. sobregeo@ig.com.br 2 GEA/UFPB, Departamento de Engenharia de Produção da UFPB.

adissi@producao.ct.ufpb.br
}

Abstract Occupational and environmental impacts connected with pesticide use have placed special emphasis on the public health. Problems caused as a consequence of this technology derive from premises diffused by the government and world-wide firms. They can be analyzed with bases on three interdependent debates: the Brazilian government's (in)capacity to inspect and also warrant the legal principles, the equipment required for the monitoring of the community health and environment, as well as the type of research to be devel oped by the research groups.

Key words Pesticides, Public health, Ecotaxes
Resumo Osimpactos de origem ocupacional e ambiental relacionados ao uso de agrotóxicos têm como alvo imediato a saú de coletiva. O s problemas gerados pela adoção desta tecnologia decorrem de premissas difundidas pelo Estado e pelas empresas-mundo podendo ser analisados à luz de três debates interdependentes: a (in)capacidade do Estado fiscalizar e garantir o cumprimento de suas normas legais, 0 aparelhamento necessário para os monitoramentos de saúde pública e ambientais requeridos e o tipo de pesquisa a ser desenvolvida pelo corpo de pesquisadores.

Palavras-chave Agrotóxicos, Saúde coletiva, Ecotaxas 
O s impactos de origem ocupacional e ambiental relacionados ao uso de agrotóxicos têm como alvo imediato a saúde coletiva. 0 entendimento dessa assertiva necessita de um aprofundamento que a substancie e permita acumular outras perspectivas sobre o tema, no sentido de alterar realidades concernentes ao uso destes insumos no Brasil e países de limitações semeIhantes.

0 presente texto vislumbra chamar a atenção para alguns obstácul os que impedem o surgimento no Brasil de uma agricultura menos agressiva à coletividade e ao ambiente. Tal esforço será feito a partir da desconstrução de premissas sobre o uso de agrotóxicos. Nessa perspectiva se discorrerá sobre três debates fundamentais para esta questão e a parte final será dedicada à análise de alternativas para o uso destas substâncias.

N esse sentido, deve ser considerado que a ditadura militar dos anos de 1960-1970 foi o momento de confluência dos interesses e ações da burguesia nacional para a modernização agrícola brasileira:

D epois, com a instalação da ditadura, essa burguesia procurou obter vantagens do governo. Crédito rural, sob todas as formas e, em geral, a juros negativos, cresceu muito. Criaram-se incentivos e favores fiscais e creditícios, para iniciar ou expandir empreendimentos agrícolas, pecuários, extrativismo agroindustrial. A celerouse o desenvolvimento do capitalismo no campo (Ianni, 1986).

Em decorrência destas ações, teve-se a difusão acelerada desses insumos por todo território nacional e que posteriormente se tornaram fundamentos indissociáveis da produção de alimentos no país. As premissas que serão aqui descritas foram construídas por intermé dio do Estado, em especial no período desenvolvimentista brasileiro entre as décadas de 1950-1970. As premissas destacadas e suas desconstruções são as seguintes:

1) Sem o uso de agrotóxicos não haverá produção de alimentos, ou esta será não economicamente viável.

Esta premissa sugere que a produção agrícola em qualquer escala é dependente dos agrotóxicos e que qualquer tentativa de abandono deste insumo pode resultar em sérios prejuízos econômicos. Guivant (1994) denomina fatalismo químico este comportamento. Trata-se de um pensamento que exclui outras alternativas e procedimentos que eliminem totalmente ou em parte o uso da química, tornando inviáveis os estudos contrários a esta lógica. Todavia, alguns órgãos oficiais de pesquisa, ONG s e iniciativas individuais têm obtido bons resultados com agricultura ecológica em suas diversas modalidades, tanto em pequena (horticultura familiar abastecedora de feiras orgânicas), quanto em larga escala (exportação de café, soja e açúcar orgânicos).

2) 0 uso adequado de agrotóxicos não produz risco ambiental e coletivo.

Esta premissa sugere que o uso de agrotóxicos, na forma prescrita por técnicos e fabricantes, não produz danos. Garcia (2001) aponta que este enfoque é "simplista e maniqueísta" ao indicar que a responsabilidade pelas intoxicações é do usuário mal preparado e que a sua educação para o uso adequado é a verdadeira solução para reduzir riscos. Discute-se, então, se os produtos técnicos, cujo princípio é a toxicidade de sua formulação, são isentos de risco se usados adequadamente. Se sua função principal é justamente intoxicar alvos biológicos, nada impede que seus ef eitos se estendam até a sociedade através do trabalho e da ingestão de água e alimentos contaminados. 0 conceito de uso adequado indica a necessidade de uma análise mais ampla do que a apresentada pelos fabricantes, pois não considera a vulnerabilidade da população usuária e os diversos ambientes técnicos de sua inserção.

3) A falta de informação dos agricultores é a maior responsável pelas contaminações ocupacionais e ambientais.

Esta premissa é uma espécie de corolário da anterior. Diante das ocorrências das intoxicações ocupacionais e contaminações ambientais, aponta o trabalhador como o responsável pelos riscos e impactos ocorridos devido à sua falta de formação técnica adequada. De fato, existe uma desinformação bastante acentuada, principalmente em função da omissão dos fabricantes, que, em seus esforços de venda, dão ênfase apenas aos resultados agronômicos e não acentuam as demais conseqüências do uso destas substâncias como relata Lutzemberger (2002). Quando se confrontam as indicações técnicas contidas nos rótulos dos produtos com a realidade do trabal ho agrícola a que se destinam, observam-se grandes incompatibilidades que vão desde uma linguagem que pressupõe uma formação técnica inexistente entre os agricultores até prescrições operacionais impossíveis de serem realizadas. Deste modo, reputar aos agricultores os impactos negativos do uso de agrotóxicos é apenas um subterfúgio para des- 
locar o debate sobre os objetivos comerciais dos fabricantes.

No caso do Brasil, estas premissas demandam três debates. 0 primeiro debate concerne à incapacidade do Estado de fiscalizar e efetivar os amplos aspectos das leis que regulamentam o uso destas substâncias na esfera do trabalho, do ambiente e da saúde. 0 segundo debate cabe à impossibilidade de aparelhar, treinar e financiar equipes de pesquisa, de fiscalização e de educação no território nacional no que tange à presença de resíduos e alterações por eles provocadas nos alimentos, na água, nos trabalhadores e consumidores. 0 terceiro debate abriga as discussões referentes à tomada de decisão do corpo nacional de pesquisadores que apostam numa ciência fortalecida por dados e descobertas concretas sobre os impactos dos agrotóxicos para assim subsidiarem mudanças de leis e procedimentos.

0 primeiro debate sobre a incapacidade do Estado em aplicar as leis tem como pano de fundo um acordo tácito e histórico entre políticos, empresários e grandes produtores de alimentos para manter as condições de produção agrícola com competitividade e lucratividade.

A efetividade da lei é prejudicada pela falta de recursos para fiscalizar e pela ausência de autoridade para aplicar as penalidades e sanções, fruto também da permissividade do Estado por não ter investido em tecnologias menos agressivas. Entre as grandes propriedades agrícolas, a ingerência política, decorrente do poder econômico, debilita a fiscalização. Entre as pequenas e médias propriedades, que abrigam grande parte dos trabalhadores assalariados não sindicalizados e dos proprietários não capacitados e sem assistência técnica, a fiscalização costuma ser sensível à precariedade social e econômica apresentada e não aplica a lei com rigor.

Alves Filho (2002), dedicando-se ao estudo da aplicabilidade do receituário agronômico, instrumento tornado obrigatório para compra de agrotóxicos a partir da instituição da Lei dos Agrotóxicos (7.802/89), aponta para a sua ineficácia como mecanismo de redução do uso não prescrito: O síndices de consumo de agrotóxicos, muitas vezes apresentados como desproporcionais em relação aos demais índices de produção, sugerem a ineficácia dos atuais sistemas de controle dos agrotóxicos, dentre os quais se inserem as atividades do receituário agronômico (Alves Filho, 2002).

Este autor avalia que a ineficácia da aplicação do receituário agronômico passa pela pró- pria insuficiência dos consel hos profissionais e governos estaduais, leia-se CREAs e Secretarias de Agricultura, em fiscalizar a expedição desses receituários. Alves Filho (2002) encontrou em seus levantamentos diversas irregularidades, como: excesso de receitas expedidas por um mesmo profissional (agrônomo de balcão); numeração incorreta e ausência de assinatura, que demonstram falhas na fiscalização. Esse mesmo autor aponta, também, que a grande maioria dos CREAs não realiza qualquer compilação das guias de receituários que recebem. Essa realidade foi constatada na Paraíba por $\mathrm{Me}$ nezes (2002), que, analisando as guias emitidas entre julho de 2000 e julho de 2001, observou que apenas $12,5 \%$ dos profissionais indicam somente produtos recomendados para cultura; os demais ( $87,5 \%$ ) apresentaram $26 \%$ de indicações irregulares para as lavouras paraibanas. Levando em consideração que se depositou demasiada responsabilidade sobre o receituário agronômico para eliminação do uso abusivo dos agrotóxicos, tem-se a partir destas constatações a noção do quanto é difícil atingir no Brasil um patamar de uso dos agrotóxicos dentro das recomendações mínimas de segurança.

No segundo debate sobre a impossibilidade de aparelhar, treinar e financiar equipes de pesquisa e de fiscal ização, percebe-se a coadunação com o debate anterior, pois o que impede a instalação de uma estrutura de monitoramento, vigilância e prevenção contra impactos dos agrotóxicos é a incapacidade do Estado em investir neste setor. A justificativa da falta de recursos deve ser montada numa perspectiva de quanto se comercializa de agrotóxicos anualmente no país.

Por outro lado, os gastos em saúde pública decorrentes das contaminações por agrotóxicos são elevados e totalmente assumidos pelo Estado e pela sociedade. No Brasil, seguindo-se a estimativa proposta pela Organização PanAmericana de Saúde(OPAS), que indica que para cada caso registrado de intoxicação por agrotóxicos outros 50 casos de intoxicação ocorreram sem notificação ou com notificações errôneas, podemos inferir que, em 1993, os 6 mil casos notificados indicam a ocorrência de 306 mil casos de intoxicação por agrotóxicos. Segundo o Guia de Vigilância Epidemiológica (1998) do M inistério da Saúde, o Sistema Ú nico de Saúde (SUS) despende, aproximadamente, $\mathrm{R} \$ 150,00$ para recuperar cada paciente vítima de intoxicação por agrotóxico. Assim sendo, podemos estimar as despesas médicas pa- 
ra o atendimento dos intoxicados de $1993 \mathrm{em}$ cerca de 46 milhões de reais. Esses gastos poderiam ter sido bastante reduzidos se as medidas de controle e de vigilância fossem mais ativas, o que demandaria maiores investimentos governamentais. No entanto, a comercialização de agrotóxicos no Brasil, que no ano de 1998 movimentou mais de 2,5 bilhões de dólares no País, está, desde 1992, isenta do I mposto sobre Circulação de M ercadorias e Serviços (ICM S). Deste modo, os recursos que poderiam ser arrecadados pelos estados são perdidos, ficando a U nião responsável por cobrir todos os outros gastos referentes ao controle e reparação dos danos decorrentes do uso de agrotóxicos, tal como os dispensados para a saúde do trabaIhador, montagem de equipes e funcionamento dos poucos e saturados laboratórios clínicos e de análise de resíduos de agrotóxicos existentes no Brasil. Se, ao contrário, os agrotóxicos fossem taxados em $12 \%$ de ICM S, como ocorre com a maioria dos alimentos brasileiros, a arrecadação gerada, algo em torno de um bilhão de reais por ano, seria suficiente para cobrir essas despesas e financiar pesquisas de tecnologias mais limpas que a agroquímica.

N ão bastasse a falta de recursos, as análises são onerosas e os equipamentos atingem a obsolescência com muita rapidez, visto que os agrotóxicos de última geração dependem de complexas metodologias para identificar e medir a extensão de seus impactos, bem como sugerem a necessidade de gastos para atualização tanto dos técnicos como dos equipamentos e métodos. Sem estes elementos, as análises serão restritas aos agrotóxicos mais conhecidos, sem poder acompanhar as novas gerações químicas que chegam ao mercado a cada ano.

0 terceiro debate sobre a postura dos pesquisadores nacionais é polêmico e interdependente aos anteriores. Alguns pesquisadores nacionais que se especializam nas análises relacionadas aos agrotóxicos depositam demasiadas esperanças em descobertas de novos indicadores de contaminação, acreditando serem a principal chave para eliminar ou controlar o uso de determinadas substâncias.

0 empenho desses pesquisadores é louvável e é oportuno que continuem na busca de indicadores de contaminação por agrotóxicos. Todavia, não se pode perder de vista que esta luta é desleal, desigual e, por vezes, imoral. A velocidade de aparel hamento e da obtenção de insumos para responder ao tamanho do problema existente no Brasil é insignificante em relação ao potencial científico e jurídico instalado junto às grandes corporações industriais do setor químico. Essas corporações atuam eficazmente na contestação da validade de qualquer prova científica que coloque em risco o mercado de seus produtos. Se a descoberta de um indicador de contaminação ambiental e humana é importante, sua utilização como parâmetro normativo enfrentará resistências das empresas e de parte da comunidade científica até ser aceito como um bom indicador.

Outro aspecto que dificulta a atividade de pesquisa, nessa área, está relacionado à epistemologia da toxicologia que pressupõe a aceitação de padrões, limites e tolerâncias aos resíduos construídos com base em um suposto "ser humano médio". Esta abstração acaba por limitar as análises dos agravos à saúde e ao meio ambiente. Com um complicador maior que éo fato de as legislações sobre os resíduos serem fundamentadas, exclusivamente, em estudos dessa natureza.

Os resultados de um grande número de estudos sobre limites residuais e seus impactos são, em sua maior parte, inconclusivos. As reticências e ponderações presentes nas conclusões de inúmeros trabalhos não são apenas resultado da cautela ou preciosismo científico nem da pretensa neutralidade científica, mas decorrem da impossibilidade de se avaliar a magnitude do impacto e, principalmente, de se demonstrar 0 nexo-causal entre uma doença ou dano ambiental e o uso de agrotóxico. Esse problema é um desafio para todos os países, embora tenha dimensões muito maiores nos países pobres.

A realidade da produção agrícola brasileira contém ainda o trabalho infantil, juvenil, de idosos e de pessoas com diversos problemas de saúde inatos ou adquiridos ao longo de seus históricos ocupacionais e coletivos. Além do que, a população de trabalhadores submetida a estas tarefas possui baixa escolaridade requerida para lidar com esse insumo. A conceituação de homem médio, "o mito operário médio" como denominou Wisner (1987), conflui para a consideração de uma população vulnerável. 0 curso básico de Vigilância Ambiental adota um conceito de vulnerabilidade bastante pertinente para a realidade brasileira:

A vulnerabilidade populacional ou populações vulneráveis relaciona-se à existência de grupos populacionais vulneráveis, de acordo com suas características em termos de status social, político e econômico, etnicidade, gênero, incapacidade, idade, etc., sendo isto derivado principal- 
mente de variadas formas e níveis de exclusão social. Se expressa em uma maior fragilidade que determinadas populações, regiões e sociedades possuem para enfrentar determinadas situações ou eventos de riscos, sendo isto resultado da maior precariedade e dificuldade em antecipar, sobreviver, resistir e recuperar-se dos impactos provenientes dos mesmos (Funasa/CBVA, 2002, apud Horlick-Jones, 1993).

Assim sendo, o contexto socioeconômico da grande maioria das zonas rurais brasileiras apresenta populações de alta vulnerabilidade, tendo em vista a pouca atenção que recebem do Estado em termos de educação, saúde, saneamento e assistência agrícola. N essas condições, os parâmetros toxicológicos dos fabricantes não podem ser transplantados tão facilmente entre populações com vulnerabilidades. Desta forma, não existiriam parâmetros toxicológicos universais, já que estes deveriam considerar as vulnerabilidades das populações expostas.

As pesquisas devem continuar em todos os sentidos, mas são necessárias medidas emergenciais com caráter cautelar, não necessariamente respaldadas por indicadores de contaminação, porém baseadas nos indícios de potenciais danos e lesões em pessoas. Sem medidas cautelares, os danos podem ser agravados e mais pessoas terão perdido a saúde ou a vida.

U m aspecto importante a ser levantado nessa discussão se refere ao âmbito de atuação dos pesquisadores das áreas de focalização da produção científica. A pesquisa científica não deve ficar limitada apenas aos ensaios laboratoriais, pois, diante da magnitude do problema encontrado no Brasil, é premente que se discuta a questão no âmbito de nossas possibilidades científicas e políticas. Pois sem considerar as questões políticas imbricadas, não ocorrerá acréscimo científico suficiente para interditar esta "catástrofe silenciosa" que representa a utilização de agrotóxicos no Brasil.

Neste ponto os três debates se confluem em único e é deste campo político que os pesquisadores não devem abrir mão de participar, pois é nele que se viabiliza o fazer de um saber científico com objetivo central de preservar a vida. A inépcia científica não pode servir para justificar a falta de ações de preservação da vida.

Desenhado o cenário dos três debates proposto no início deste texto, cabe complementar a discussão apontando algum tipo de alternativa. Pode-se vislumbrar distintos campos de ação: ações de monitoramento dos impactos negativos do uso de agrotóxicos, ações de inibi- ção ao uso de agrotóxicos e ações de conversão tecnológica.

Como foi afirmado anteriormente, monitorar as conseqüências danosas dos agrotóxicos é dispendioso. Estes custos podem ser atenuados se for somada aos esforços oficiais a participação da comunidade organizada, ONGs e outras entidades na realização de levantamentos e diagnósticos de riscos que servirão de indicadores para ações de saúde e de proteção ambiental.

As ações de inibição deverão se estruturar a partir da mobilização da sociedade para efetivação da legislação pertinente, enfraquecendo os lobbies dos fabricantes através de campanhas de esclarecimento sobre os impactos negativos dos agrotóxicos. Outra linha de ação seria a criação de instrumentos econômicos na forma de ecotaxas que compensassem os custos sociais e ambientais decorrentes desta opção tecnológica.

Associada à ecotaxa, deve-se restabelecer os impostos sobre agrotóxicos ou ampliar o conceito de impostos ambientais promovendo tributação que sirva como instrumentos econômicos para gestão ambiental equivalentes aos que são adotados em países da Europa como apontam M ota \& Young (1997).

A justificativa para esta cobrança é a mesma que serve de base para a cobrança de taxas do álcool e dos cigarros no Brasil, quer dizer, se os agrotóxicos são reconhecidamente substâncias que provocam lesões crônicas, tal como álcool e o cigarro, os impostos fortaleceriam a previdência nacional no sentido de ampliar os benefícios concedidos aos trabal hadores lesionados, inválidos e familiares de trabalhadores mortos. A cobrança deste imposto também é importante para que existam informações sobre a circulação destas mercadorias visto que com a isenção vigente não é possível verificar 0 consumo de agrotóxicos nos estados e municípios, senão através das informações disponibilizadas pela Associação Nacional de D efesa Vegetal (ANDEF), órgão de representação das indústrias produtoras de agrotóxicos.

Além de servir para a previdência, a cobrança de ecotaxa sobre agrotóxico serviria também para a criação de fundos para o estabelecimento de programas de conversão tecnológica para a produção limpa. A superação da agroquímica só será possível mediante uma política agrícola que privilegie o investimento em pesquisa em agroecologia e sua difusão apoiada em créditos agrícolas diferenciados. 


\section{Referências bibliográficas}

Alves Filho JP 2002. U so de agrotóxicos no Brasil: controle social e interesse corporativo. Annablume, São Paulo.

Campos LPR 1997. ICM S Ecológico: experiências nos estados do Paraná, São Paulo, M inas Gerais e alternativas na Amazônia. In Programa-piloto para proteção de florestas tropicais. Disponível em <http://www. mma.gov.br/>. Acesso em 8 de setembro de 2002.

Decreto no 23.325/02, de 29.8.02. DOE de 30.8.02. Regulamento do imposto sobre operações relativas à circulação de mercadorias e sobre prestações de serviços de transporte interestadual e intermunicipal e de comunicação-RICM S. Disponível em <http://www.sefin. pb.gov.br/index.htm>. Paraíba.

Funasa/CBVA 2002. Curso Básico de Vigilância Ambiental - M ódulo 3. Agência de Vigilância Ambiental, Brasília.

Garcia EG 2001. Segurança e saúde no trabalho rural: a questão dos agrotóxicos. Fundacentro- M inistério do Trabalho e Emprego, São Paulo.

Guia de Vigilância Epidemiológica 1998. Centro Nacional de Epidemiologia - CENEPI/FNS, Brasília.
Guivant JS 1994 A percepção dos olericultores da grande Florianópolis (SC) sobre os riscos decorrentes do uso de agrotóxico. Revista Brasileira de Saúde 0 cupacional 22(82):47-57.

Ianni 0 1986. Ditadura e agricultura: o desenvolvimento do capitalismo na A mazônia 1967-1978. Civilização Brasileira, São Paulo.

Lutzemberger J 2002. A grotóxicos. Traduzido por M arcia Valarezo e Lilly Charlotte Lutzemberger. Disponível em <http://erp.org.ar/ecos/AGROTOXICOS.htm>, acesso em outubro de 2002.

M enezes LC 2002. Análise do consumo de agrotóxico na Paraíba através dos receituários agronômicos emitidos (jul/00-jun/01). Relatório de pesquisa, PIBIC/ UFPB/CNPq, João Pessoa.

M ota RS \& Young CEF 1997. Instrumentos econômicos para a gestão ambiental no Brasil. Rio de Janeiro, 1997. Disponível em < http://www.mma.gov.br/> , acesso em 8 de setembro de 2002.

Wisner A 1987. Por dentro do trabalho. Ergonomia: método e técnica. FTD-O boré, São Paulo.

Artigo apresentado em 1의/7/2003

Aprovado em 2/9/2003

Versão final apresentada em 19/9/2003 